\title{
Fotografia como referência visual em processos criativos na pintura: buscando uma tradição
}

\author{
Priscilla de Paula Pessoa ${ }^{7}$ \\ DOI 10.20396/eha.vil4.3404
}

No processo criativo de pintores, especialmente figurativos, fotografias são constantemente tomadas como ponto de partida para pensar o olhar e organizar a imagem antes e durante a fatura de pinturas. A pesquisa que desenvolvo dentro do programa de doutorado em Estudos de Linguagens da UFMS pretende levantar e analisar diferentes estratégias adotadas por artistas contemporâneos brasileiros na utilização de fotografias como referências visuais para a produção de suas pinturas, investigando possibilidades e convergências deste cruzamento. Tal expediente, no entanto, não é novo; podemos afirmar que os artistas atuais que adotam esta estratégia criativa se inserem numa certa tradição, e, a seguir, apresento alguns apontamentos extraídos da parte da pesquisa que se dedica a levantar um aporte histórico sobre a relação entre fotografia e pintura, dentro de processos criativos que entregam ao público obras pictóricas.

Desde que, no século XV, os pintores europeus retomaram a ambição grega do naturalismo, iniciou-se a busca por métodos que auxiliassem a reproduzir nas telas e paredes uma "ilusão convincente das coisas do mundo"2; dentre tais métodos, aponta-se para o uso recorrente de câmeras escuras $^{3}$. Foram poucos os artistas que registraram, nos documentos que produziram sobre seus processos criativos, o uso desta estratégia; todavia, apesar da carência de depoimentos ou outros documentos da época, estudos como o de David Hockney apontam para essa relação antiga entre imagem projetada e imagem pintada4: segundo o autor, gênios da pintura como Jan Van Eyck (c. 1390 - 1441) Caravaggio (1571 - 1610) e Johannes Vermeer (1632 - 1675), entre muitos outros, teriam utilizado tal expediente para facilitar e tornar mais verossímil a passagem entre o que se vê para o que se pinta, ou seja, entre referência visual e obra.

\footnotetext{
1 Mestre e doutoranda em Estudos de Linguagens, ambos pela Universidade Federal do Mato Grosso do Sul (UFMS). Também é professora adjunta e pesquisadora, na mesma instituição.

2 OSBORNE, 1976, p. 54

3 De acordo com Hockney (2001), a câmera escura consiste num espaço fechado (uma caixa ou mesmo um quarto) onde há um buraco, por vezes dotado de lente, pelo qual a luz externa passa e atinge o interior, em cuja superfície a imagem invertida é reproduzida; em seu conceito está a base para a invenção da fotografia. $\mathrm{O}$ artista enxerga a projeção do objeto original e pode passar o lápis ou pincel por cima da imagem que vê, desenhando-a num suporte.

4 HOCKNEY, 2001
} 
Assumindo esta teoria como sendo verdadeira, resta a dúvida: por que o uso da câmera escura era mantido em segredo pelos citados artistas e por tantos outros entre os séculos XV e XIX? Acredita-se que os artistas escondiam sua maneira de captar e fixar a referência imagética para resguardar seus métodos e proteger-se da concorrência com outros artistas (que era muito acirrada), e mesmo para se precaver dos perigos da Inquisição:

Na aurora da Renascença, as habilidades dos vários ofícios e profissões eram propriedade coletiva dos seus praticantes. As guildas muitas vezes protegiam com unhas e dentes a perícia local, sobretudo se esta fosse o fundamento da sua prosperidade. Hoje, as indústrias de alta tecnologia protegem seu know-how com acordos draconianos de não divulgação. Não foi muito o que mudou! Para algo aparentemente tão mágico como uma projeção havia outras razões para sigilo [...] Cento e cinquenta anos antes de Van Eyck os conservadores da Igreja haviam tornado essa cautela obrigatória, sob pena de excomunhão ou pior. ${ }^{5}$

Já o uso de fotografias propriamente ditas ${ }^{6}$ como referência visual durante o processo criativo de pinturas, remonta a meados do século XIX, marcando a convergência entre a invenção recente de um processo mecânica de produção de imagens e as novas propostas na seara da pintura, que culminariam com a ruptura com a tradição, característica do século XX. Na década de 1850 Gustave Courbet (1819 - 1877) já costumava "transpor para a pintura imagens extraídas de fotografias"; Mais tarde, "Manet e Degas pensavam o instantâneo fotográfico e seus enquadramentos".

Tomando como exemplo obras justamente de Gustave Courbet e Edgar Degas (1834 - 1917), é possível observar dois caminhos distintos que artistas podem seguir em suas pinturas a partir da referência fotográfica, em operações que ainda hoje observamos nos ateliês. Nas figuras 01 e 02, vemos reproduções de uma pintura de Courbet e da fotografia na qual o artista baseou-se, e é flagrante como a utiliza como norteadora durante toda a fatura de sua obra - o enquadramento, a composição, a iluminação, são fielmente transpostos à tela. Já na comparação entre as figuras 03 e 04 nota-se que Degas usa como referência apenas a estrutura anatômica da banhista, iluminando -a a seu gosto e "montando-a" sobre um cenário baseado em outra referência, que desconhecemos. Partindo dessas imagens, percebe-se que pintores contemporâneos aos primórdios da fotografia, por vezes, submetem-se ao seu fascínio e intentam transpor o que vêem impresso, tal e qual, para a

\footnotetext{
5 HOCKNEY, 2001, p. 216

6 Durante a primeira metade do séc. XIX descobrem-se diversos métodos fixadores das imagens ópticas, através de processos químicos; tal imagem fixada passa a ser comumente chamada, a partir do século XX, de fotografia; a primeira de que se tem notícia, de acordo com Argan (2006) data de 1826 e foi produzida pelo francês Joseph Nicéphore Niépce.

7 ARGAN, 2006, p.81

8 MESQUITA, 2012, p. 271
} 


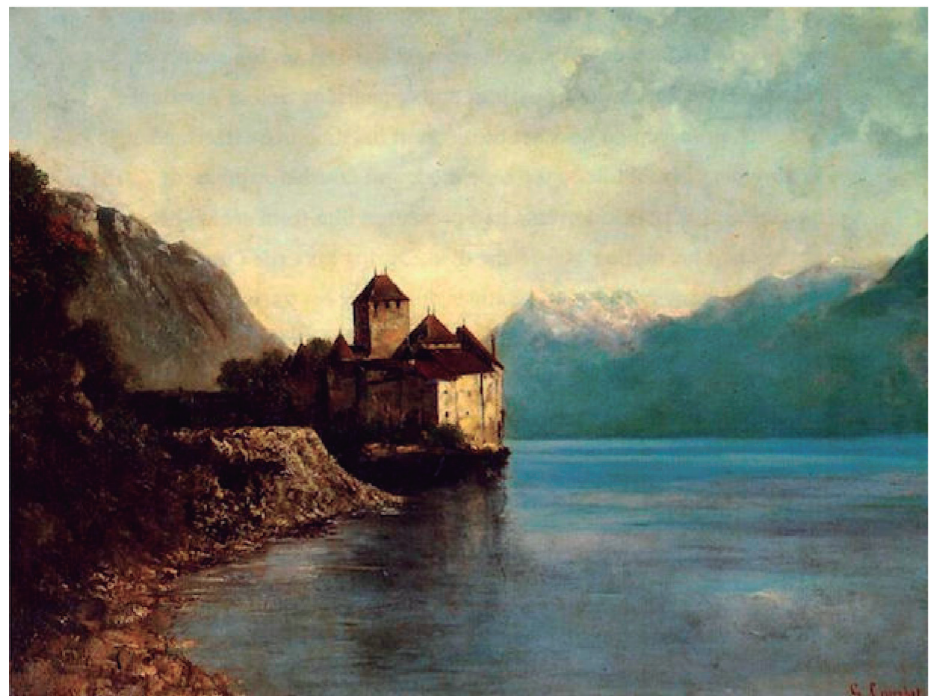

[Figura 01] Gustave Courbet. Castelo de Chillon, 1874.

Óleo s/ tela. 86 × $100 \mathrm{~cm}$. Musée Gustave Courbet, Ornans. Disponível em $<$ http://warburg.chaa-unicamp.com.br/obras/>. Acesso em 25 de out. de 2019.

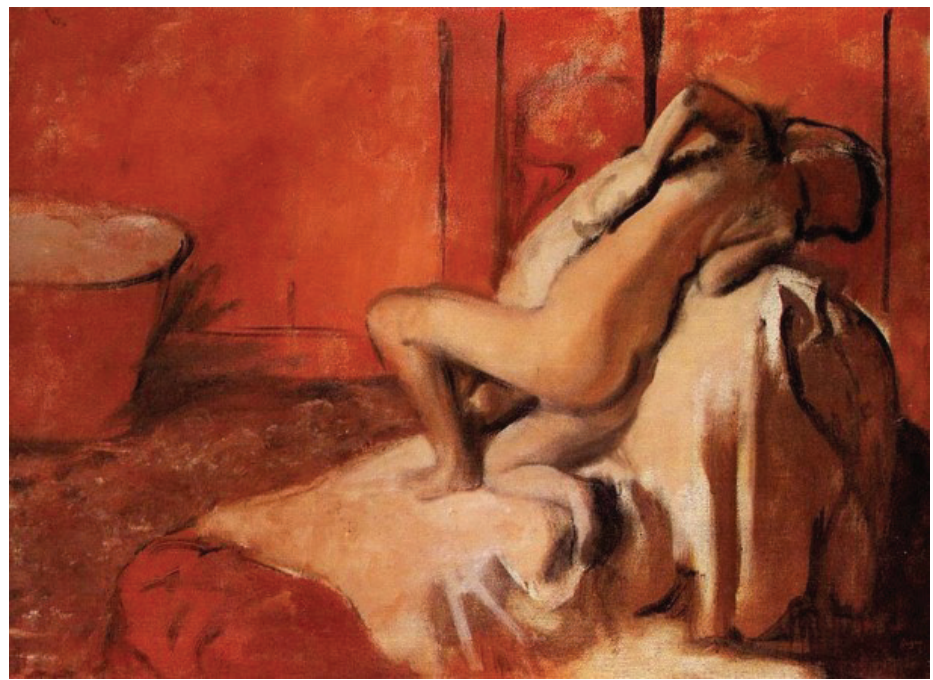

[Figura 03] Edgar Degas. Depois do Banho. 1896.

Óleo s/tela. 89x 116 cm. Philadelphia Museum of Art. Fonte: EDINGER (2019, P. 46)

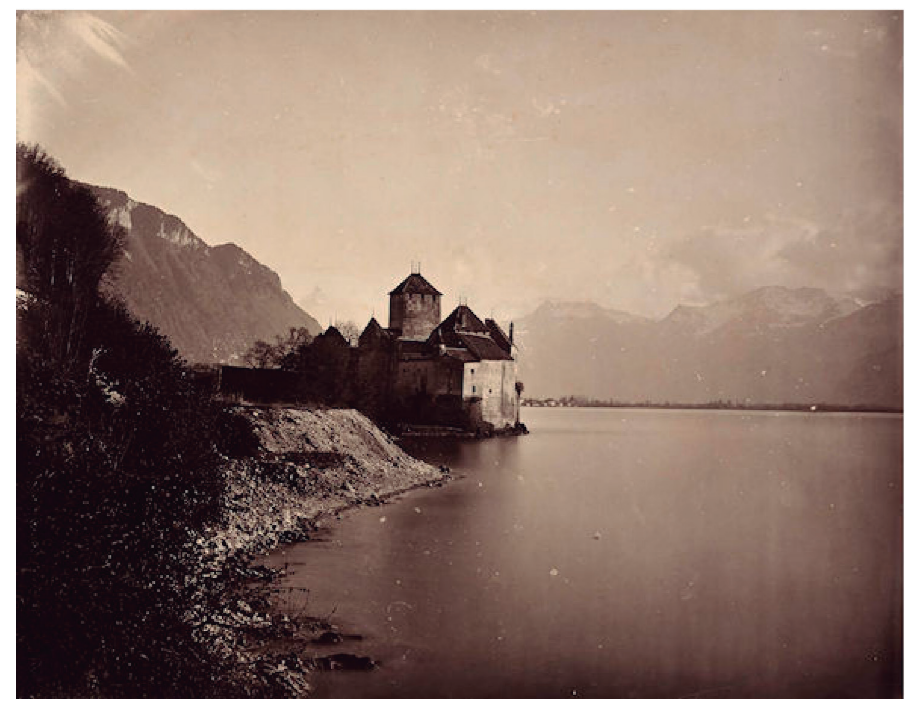

[Figura 02] Adolphe Brawn. Castelo de Chillon, 1863.

Fotografia em albumina. $36,8 \times 42,7 \mathrm{~cm}$. Museum og fine arts, Boston. Disponível em <http://warburg.chaa-unicamp.com.br/obras/ >. Acesso em 25 de out. de 2019.

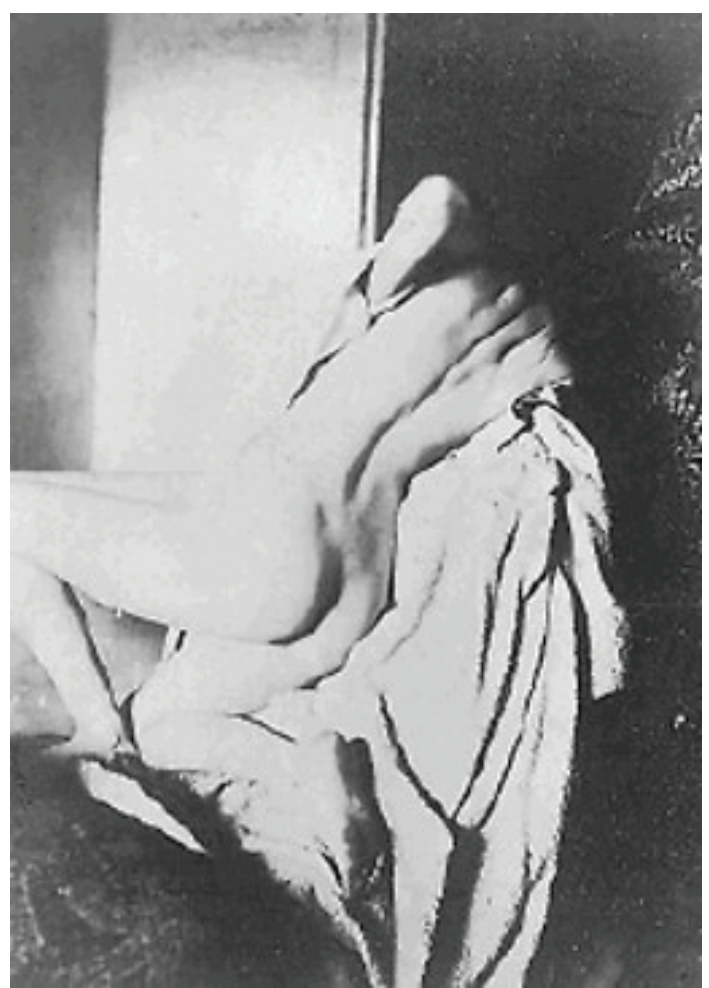

[Figura 04] Edgar Degas. Depois do Banho. 1896. Impressão em gelatina de prata. Museu ]. Paul Cetty, Los Angeles. Fonte: EDINGER (2019, P. 46) 
tela; e por vezes entendem a imagem como um referencial que é apenas uma das partes (geralmente inicial) do seu processo criativo, e se serve dela mais livremente.

Ainda no século XIX, foi documentado ${ }^{9}$ o uso recorrente de fotografias que serviram a artistas como Eugéne Delacroix (1798 - 1893), Jean-Auguste Ingres (1780-1867), Paul Cézanne (1839 -1906), Paul Cauguin (1848-1903), Tolouse Lautrec (1864-1901), Dante Gabriel Rosseti (1828 - 1892), entre tantos outros. No caso de todos os artistas citados acima, além da mesma liberdade em relação à imagem de base notada no exemplo de Degas, vale também registrar que as fotografias não foram destruídas: pelo contrário, muitas vezes foram arquivadas por eles mesmos, o que demonstra que manter segredo, guardado à sete chaves pelos predecessores usuários das câmeras escuras, já não preocupava esta geração. A crítica genética agradece!

Continuando a abordagem sobre os artistas europeus da segunda metade do século XIX, outro ponto a salientar é o fato das fotografias não serem, no mais das vezes, de autoria dos pintores (Degas é uma exceção), mas obtidas de outras maneiras. Uma possibilidade era que fossem produzidas por fotógrafos profissionais sob encomenda para determinada pintura, atendendo assim características que um pintor desejasse nestas imagens, que já nasciam para servir de referência, como no caso das fotografias usadas por Ingres nos retratos feitos em sua velhice - cujo procedimento foi registrado no depoimento do jornalista Eugéne Mirecourt:

Nadar é o único fotógrafo a quem ele envia pessoas de quem ele quer ter uma perfeita semelhança. As fotografias de Nadar são tão esplendidamente exatas que o senhor Ingres, com o auxílio delas, compõe os mais admiráveis retratos sem nenhuma necessidade da presença do original. ${ }^{10}$

Sabemos também que muitas vezes o artista encontrava ou comprava fotografias já existentes e que Ihe serviriam de referência, especialmente pelo tema que abordassem. Eram fotografias adquiridas como parte de álbuns ou cartões postais, mas também podiam ser compradas de fotógrafos que as produziam pensando nessa clientela específica; por exemplo, o francês Eugène Atget mantinha em seu estúdio fotográfico uma placa em que se lia "documentos para artistas". Com efeito, há registros de que ele forneceu fotografias (que ele chama de documentos) "para pintores, arquitetos e cenógrafos"11, dentre eles Andre Derain (1880 - 1945) e Ceorges Braque (1882-1963).

Ainda um terceiro procedimento de obtenção da fotografia, que surge no século XIX, (e que

\footnotetext{
9 EDINGER, 2019

10 HOCKNEY, 2001, p.16

11 EDINGER, 2019, p. 62.
} 
ocorre ainda hoje) pode ser exemplificado a partir do que se conhece sobre o processo criativo da pintura Batalha de Campo Grande (figura 05), do brasileiro Pedro Américo (1843-1905). Para pensar sua obra, o artista valeu-se não de uma fotografia, mas de ao menos três, criando sua composição a partir destas imagens em que apareciam retratos de homens que participaram da batalha, à qual o artista desejava aludir o mais fielmente possível ${ }^{12}$. Assim, ele parte não de uma única referência fotográfica, mas de várias, valendo-se também de referências de outras ordens, como descrições de vestimentas e paisagens, modelos vivos e mesmo reproduções de outras pinturas.

Já na primeira metade do séc. XX o rompimento com os temas clássicos da pintura vem acompanhado, no mais das vezes, pela superação das tentativas de representação ilusionística. Segundo Clement Greenberg ${ }^{13}$, a maior premissa da pintura moderna é a de que ela deve mostrar os limites e os meios da própria pintura, comportando-se assim, em detrimento da narrativa. Nesse período, a fotografia ainda serve como referência no processo criativo de artistas das vanguardas fauvistas, futuristas, cubistas, entre outras; mas seu papel é muito mais de apoiar a desconstrução do real do que o de auxiliar sua apreensão. Isto é bem explicitado ao observarmos a relação que Picasso estabelece com as fotografias, recurso bastante presente no processo criativos de todas as suas fases. Por mais que, observando pinturas deste artista, como Les demoiselles d'Avignon (figura 06) a princípio pareça disparatado relacioná-la diretamente com alguma imagem fotográfica, como a da figura 07, é preciso ter em mente que:

Para a maioria das pessoas, Picasso é conhecido como pintor e escultor. No entanto Picasso utiliza a fotografia como bloco de notas desde o começo do século XX. O Museu Picasso, em Paris, tem vários arquivos documentando a relação íntima de Picasso com a fotografia: ele fotografava, revelava e ampliava as imagens. Muitas vezes, usava as fotos para fazer quadros. (...) A quantidade de fotos reunidas no livro espetacular da curadora do museu do Picasso em Paris, Anne Baldessari, é assombrosa (Picasso and Photography - The Dark Mirror. No livro Baldessari escreve: "Durante décadas Picasso usa a fotografia como pesquisa de seu trabalho, combinando seus desenhos com imagens fotográficas." Picasso não só fazia retratos e autorretratos, mas utilizava a fotografia principalmente para cristalizar suas ideias e para se inspirar."14

Em outro exemplo modernista, a sede de artistas futuristas por representar dinamismo e simultaneidade num espaço pictórico bidimensional é por vezes inspirada - se não intermediada -

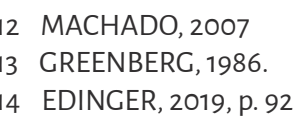




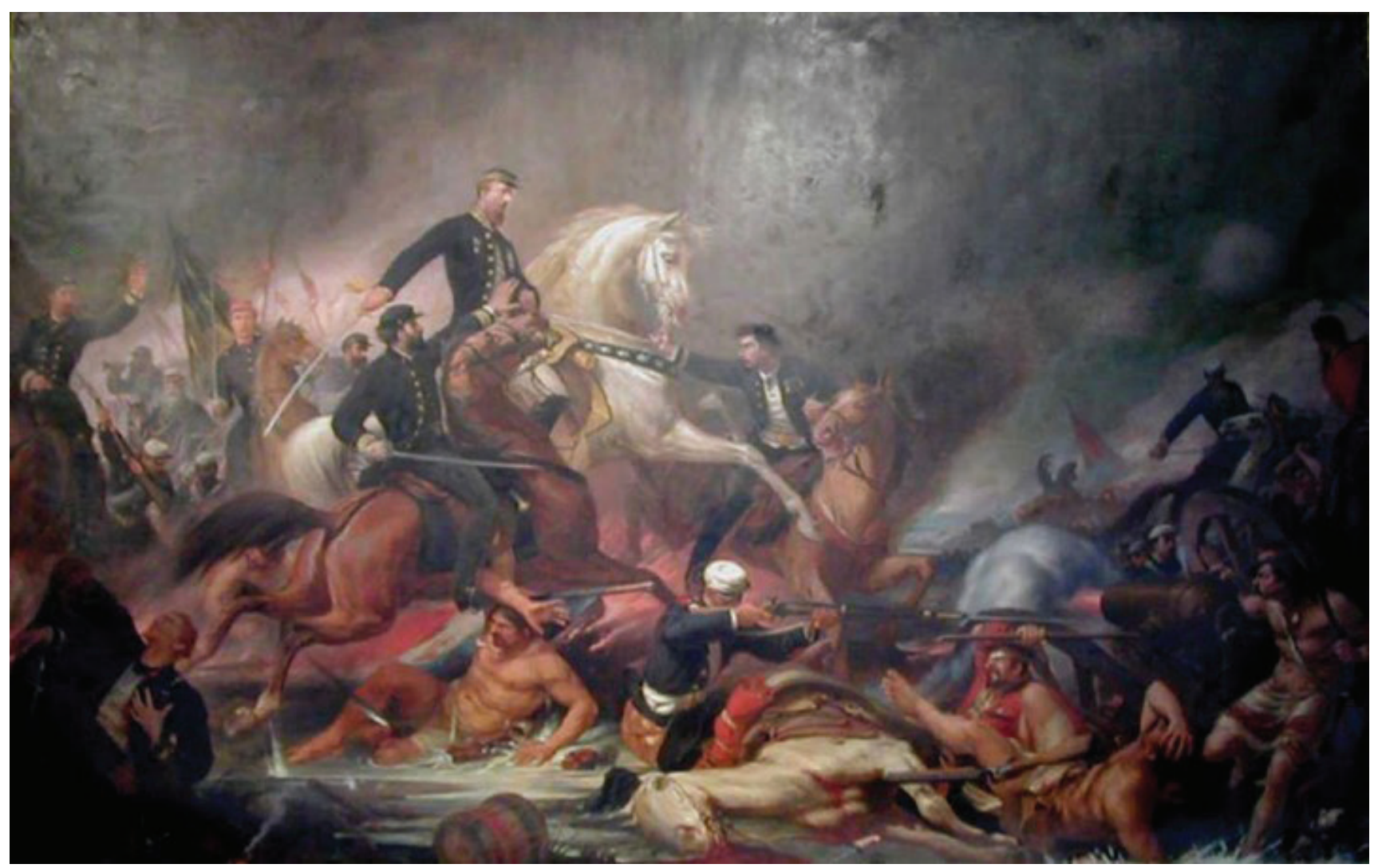

[Figura 05] Pedro Américo. Batalha de Campo Grande. 1871.

Óleo s/tela, $332 \times 530 \mathrm{~cm}$. Petrópolis, Museu Imperial. Fonte: <http://www.dezenovevinte.net/obras/pa_foto.htm>. Acesso em 25 de out. de 2019.

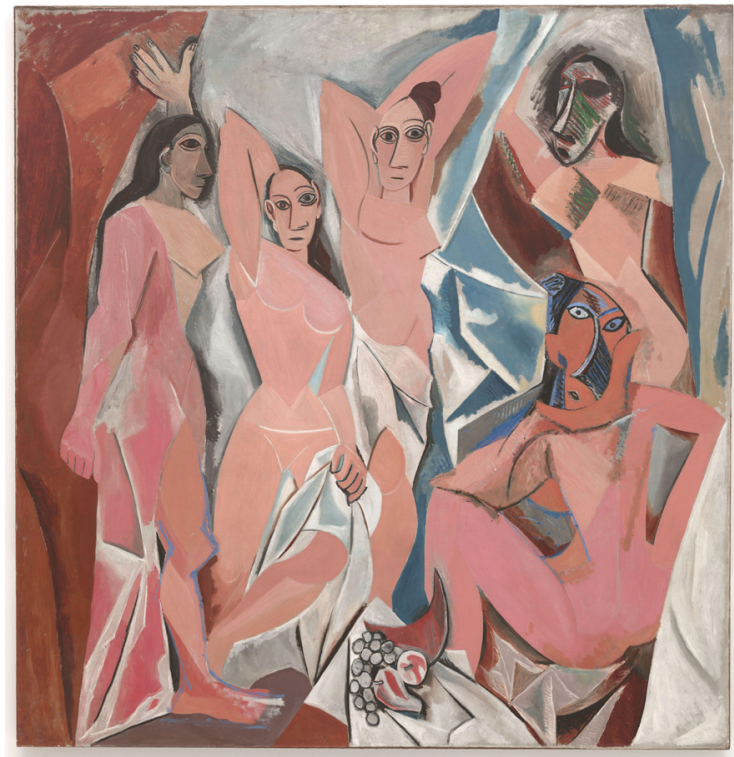

[Figura 06] Pablo Picasso. Les demoiselles d'Avignon. 1907.

Óleo s/ tela, 243.9 × $233.7 \mathrm{~cm}$. Museu de Arte moderna de New York. Fonte: EDINGER (2019, p. 93).

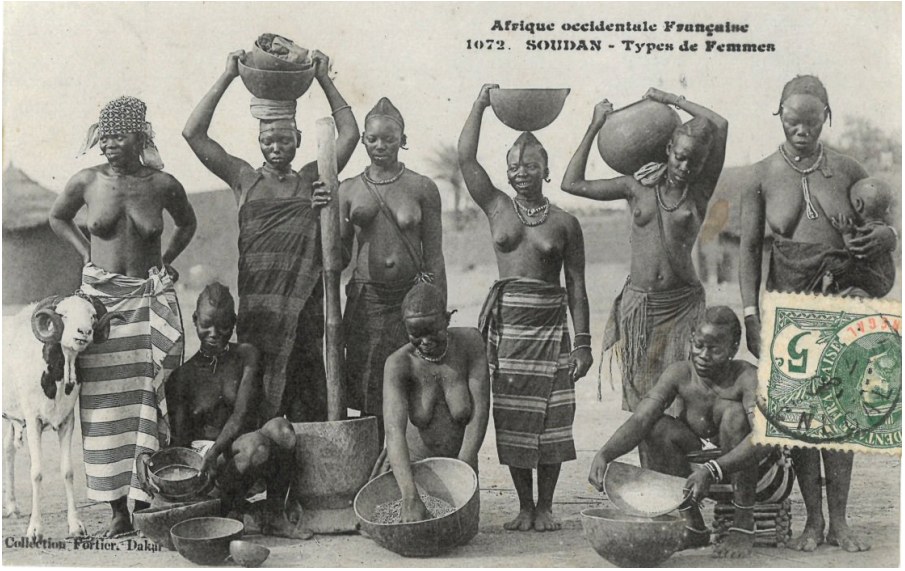

[Figura 07] Edmond Fortier. Cartão postal retratando mulheres senegalesas do início do século XX, utilizada por Picasso como inspiração para Les demoiselles d'Avignon. Data desconhecida.

Fonte: EDINCER (2019, P. 93). 
por cronofotografias (figura 08), e o resultado são pinturas em que se sobrepõem "fases sucessivas de movimento umas nas outras, como na exposição múltipla da fotografia"15. Na cronofotografia a imagem do corpo era registrada em diferentes posições em sequência, permitindo visualizar o deslocamento em distintos momentos no tempo. Na pintura Nu descendo a escada (figura 09), Marcel Duchamp (1887-1968) tem como referência a técnica da cronofotografia ${ }^{16}$.

Ainda dentro da primeira metade do século XX, há de se ressaltar (mesmo que não seja o foco da pesquisa que desenvolvo) a prática da colagem de fotografias em pinturas cubistas, dadaístas, surrealistas e da Pop Art, entre outras vertentes que fizeram uso deste recurso; nestes casos, as fotografias não servem de referência para a produção de pinturas: são elas mesmas inseridas no espaço plano da tela, antes domínio absoluto do pictórico na arte.

Mas nem só de rupturas com a representação ilusionística se fez a pintura do século XX. “Em torno da década de 1930, alguns artistas modernos quiseram voltar ao passado. Resolveram pintar as figuras da maneira como elas eram feitas antes das vanguardas"17. Desde então, mesmo sem o mesmo estrondo das vanguardas, alguns movimentos (como a Nova Objetividade e o Realismo Socialista), além de artistas isolados como Edward Hopper (1882 -1967) e Lucian Freud (1922 - 2011), no decorrer do século cultivaram a proximidade entre o que se vê e o que se pinta. No que tange especificamente ao uso da fotografia como referência, destaco a tendência hiper-realista na pintura, que se irradia a partir dos EUA da década de 1960 e tem ecos ainda hoje. Nela, o artista ambiciona atingir a imagem em sua máxima clareza objetiva (como podemos observar no exemplo da figura 10) e há algumas premissas para se considerar uma obra como hiper-realista ${ }^{18}:$ o uso exclusivo da fotografia para coletar informação; o uso de recursos mecânicos ou semi-mecânicos para transferir a informação para a tela; a habilidade do artista para fazer com que a pintura se pareça com uma fotografia.

Apesar de cair imensamente no gosto de colecionadores e de ser hoje vastamente difundida em postagens de redes sociais virtuais, a pintura dos hiper-realistas teve críticos ferrenhos, como Giulio Carlo Argan, que afirma que "a literalidade da imagem, elaborada de maneira puramente técnica e segundo uma técnica convencional, paralisa na origem todo possível movimento da imaginação"19. Sem entrar no mérito da análise crítica dos métodos e resultados da pintura, o fato é que

\footnotetext{
15 JANSON, 2001, p.968

16 MACHADO, 2007

17 MESQUITA, 2012: p. 270

18 MEISEL, 1980

19 ARGAN, 1974 apud FABRIS, 2013, p. 238
} 


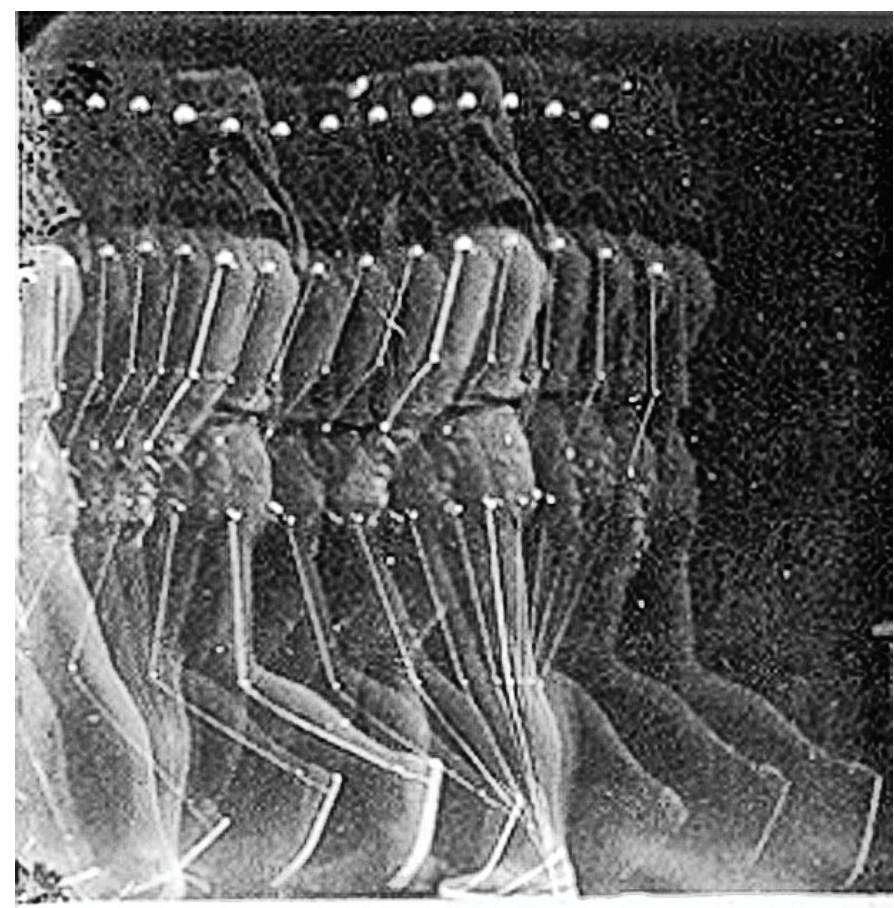

[Figura 08] Etienne Marey. Estudos sobre a marcha da figura humana (detalhe). 1884.

Cronofotografia. Fonte: <https://msu.edu/course/ha/240/duchamp.htm>. Acesso em 25 de out. de 2019.

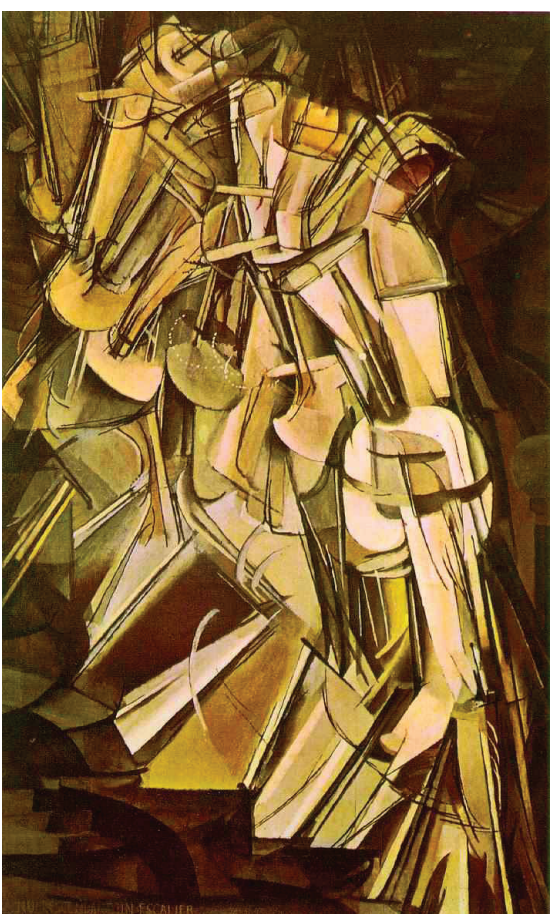

[Figura 09] Marcel Duchamp. Nu descendo a escada n. 2. 1912.

Óleo s/tela. 147X $89 \mathrm{~cm}$. Museu de Arte da Filadelfia. Fonte: EDINGER (2019, P. 40).

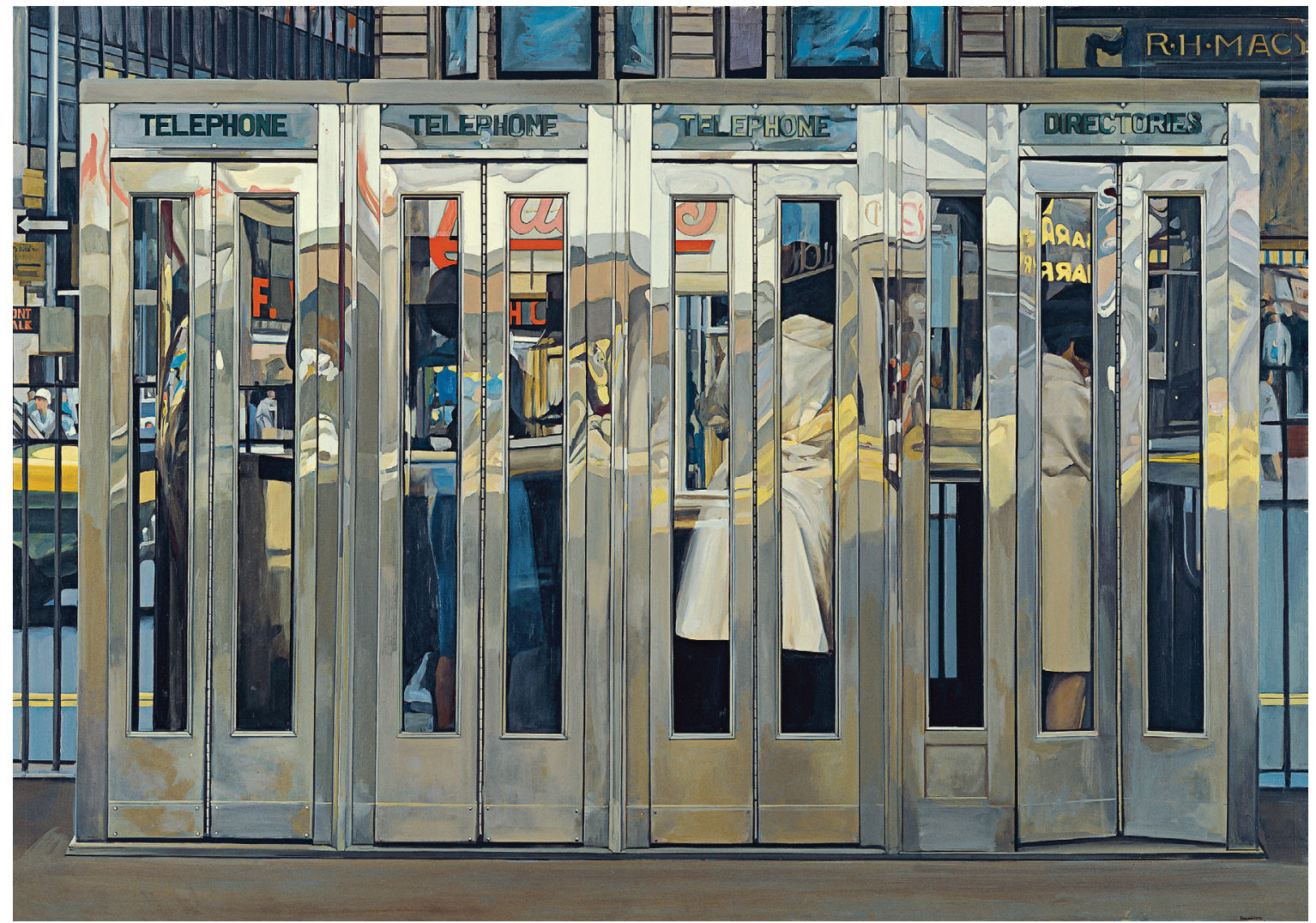

[Figura 10] Richard Estes. Telephone Booths. 1967.

Acrílica s/madeira. $122 \times 175.3 \mathrm{~cm}$. Museu Thyssen-Bornemisza, Madrid. Fonte: < https://www. museothyssen.org/en/collection/ artists/estes-richard/telephone-booths>. Acesso em 25 de out. de 2019. 
nunca antes dos hiper-realistas o papel da fotografia como referência foi tão explícito (tanto que outra denominação da tendência é fotorrealismo).

Fecha-se, assim o ciclo deste breve recorte histórico sobre o uso de fotografia no processo criativo de pinturas, que nos permite vislumbrar ao mesmo tempo a antiguidade e a atualidade de procedimentos e intenções por parte dos pintores ao valer-se de tal estratégias. Tanto é assim que o presente texto inicia-se e é encerrado relatando os extremos da vontade de artistas - do século XV e do século XX - de aproximar-se daquilo que enxergam: a vontade naturalista, presente tanto em renascentistas como em hiper-realistas, usando para isso câmeras escuras e seus desdobramentos para obter referências fotográficas que sirvam ao seu processo criativo.

Referências Bibliográficas

ARGAN, Giulio Carlo. Arte Moderna. 5a. ed. São Paulo: Companhia das Letras, 2006.

BENTO, José. Pintura Brasileira no Séc. XXI. Rio de Janeiro:Cobogó, 2012.

EDINGER, Claudio. Historia da fotografia autoral e a pintura moderna. São Paulo: Ed. Ipsis, 2019

FABRIS, Annateresa. O debate crítico sobre o Hiper-realismo. Revista ArtCultura, Uberlândia, v. 15, n. 27., jul./dez. 2013. Dísponível em: <http://www.artcultura.inhis.ufu.br/>. Acesso em 20 de jul. 2015.

GREENBERG, Clement. A Pintura Moderna. In BATTOCK, Gregory. A nova arte. São Paulo: Perspectiva, 1986.

HOCKNEY, David. O Conhecimento Secreto: redescobrindo as técnicas perdidas dos grandes mestres. $1^{\text {a }}$. Ed. São Paulo: Editora Cosac Naify, 2001.

JANSON, Horst. História geral da arte. São Paulo: Martins Fontes, 2001.

MACHADO, Arlindo. Arte e Mídia, aproximações e distinções. Rio de Janeiro: Ed.Jorge Zahar, 2007.

MACHADO,Vladimir. 1871: A fotografia na pintura da Batalha de Campo Grande de Pedro Américo. 19\&20, Rio de Janeiro, v. II, n. 3, 2007. Disponível em: <http://www.dezenovevinte.net/obras/pa_foto.htm>. Acesso em 13 de dez. de 2019.

MEISEL, Louis. Photorealism. New York: Harry N. Abrams Publishers, 1980.

MESQUITA,Tiago. A pintura de imagem. In: BENTO, José. Pintura Brasileira no Séc. XXI. Rio de Janeiro:Cobogó, 2012. OSBORNE, Harold. Estética e teoria da arte. $2^{a}$ ed. São Paulo: Cultrix, 1976 